\title{
Determinants of peri-operative blood transfusion in a contemporary series of open prostatectomy for benign prostate hyperplasia
}

Mathew Y. Kyei, George O. Klufio, James E. Mensah, Samuel Gepi-Attee, Kwabena Ampadu, Bernard Toboh and Edward D. Yeboah

\begin{abstract}
Background: The objective of this study was to determine the factors responsible for peri-operative blood transfusion in a contemporary series of open prostatectomy for benign prostate hyperplasia and thus offer a guide for blood product management for the procedure.

Methods: This was a prospective study of 200 consecutive patients who underwent open prostatectomy for BPH from January 2010 to September 2013 at the Korle Bu Teaching Hospital, Accra. The data analyzed included the pre-operative blood haemoglobin level $(\mathrm{Hb})$, presence of co-morbidities, the case type, indication for the surgery, ASA score, anaesthetic method used, systolic blood pressure, status of the operating surgeon, duration of surgery and the operative prostate weight. The transfusion of blood peri-operatively was also documented.

Results: The mean age of the patients was 69.1 years. Elective cases formed $83.5 \%$ with refractory retention of urine being the commonest indication for surgery $(68.0 \%)$. The mean pre-operative Hb was $12.1 \mathrm{~g} / \mathrm{dl}$. Consultants performed $56.0 \%$ of the prostatectomies. Transvesical approach was used in $90.0 \%$ of the cases. The mean operative time was 101.3mins (range 35.0-240.0) with a mean operative prostate weight of $110.8 \mathrm{~g}$ (range 15-550 g). Most of the patients $(82.0 \%)$ had spinal anaesthesia. The blood transfusion rate was $23.5 \%$. The transfusion rate was significantly higher in patients with anaemia $(p=.000)$, emergency cases $(p=.000)$, the use of general anaesthesia $(p=.002)$, a resident as the operating surgeons $(p=.034)$, prostate weight $>100 \mathrm{~g}(p=.000)$ and duration of surgery $(p=.011)$. In a multivariable logistic regression analysis however only the pre-operative $\mathrm{Hb}(p=.000$. OR $0.95,95 \% \mathrm{Cl}[0.035-0.257])$ and the duration of surgery $(p=.025, \mathrm{OR} 1.021,95 \% \mathrm{Cl}[1.003-1.039])$ could predict blood transfusion in open prostatectomy for BPH in this series.

Conclusions: A 'group and save' policy should be the preferred blood ordering procedure for patients with $\mathrm{Hb} \geq 13.0 \mathrm{~g} / \mathrm{dl}$ scheduled for an elective open prostatectomy for BPH under spinal anaesthesia. A long operative time however may increase the need for blood transfusion.
\end{abstract}

* Correspondence: matkyei@yahoo.com

Department of Surgery and Urology, School of Medicine and Dentistry,

College of Health Sciences, University of Ghana, P. O. Box 4236, Accra, Ghana 


\section{Background}

Open prostatectomy for the surgical management of benign prostate hyperplasia (BPH) is now rarely used in most developed countries except for large prostates $[1,2]$. This exclusive indication for the procedure in these countries is currently being shared with newer modalities of treatment like the holmium laser resection of the prostate [3]. However in resource poor countries, open prostatectomy remains the main mode of surgical management of benign prostate hyperplasia irrespective of the prostate size [4]. The surgical outcomes of open prostatectomy for $\mathrm{BPH}$ continue to be the basis for comparing and evaluating the effectiveness and safety of the newer methods of surgical management of large prostates [5]. This is because of the excellent clinical outcomes with improvement in lower urinary tract symptoms and an observed lower failure rate [5]. Thus a report on contemporary series of open prostatectomy in this era of newer treatment modalities may provide useful information in relation to blood transfusion requirements as we evaluate these newer techniques.

A frequently encountered challenge in open prostatectomy compared to the newer methods of surgical management of $\mathrm{BPH}$ is peri-operative bleeding requiring blood transfusion. The reported blood transfusion rates in open prostatectomy for $\mathrm{BPH}$ range from $3.3 \%$ to $36.8 \%[2,5-8]$. Blood transfusion carries risk of transfusion reactions and disease dissemination $[9,10]$ and there is substantial economic cost associated with allogeneic transfusions [11]. In developing countries where open prostatectomy is currently mostly practiced, assess to blood for transfusion is limited as there are only few voluntary blood donors. These surgeries are sometimes unduly delayed on account of lack of acceptable blood donors. An understanding of the factors that determine the transfusion rate in a contemporary series of open prostatectomy for $\mathrm{BPH}$ may form the basis for deciding pre-operatively, the likelihood of needing blood transfusion in a particular operation. This will enable a more rational ordering of blood products for the procedure as part of a blood management strategy. It will also bring to light modifiable factors that when addressed, could potentially make the transfusion rate in open prostatectomy comparable to the newer minimally invasive methods of prostatectomy for $\mathrm{BPH}$.

\section{Methods}

This was a prospective study on the management of 200 consecutive patients who had consented in writing to undergo open prostatectomy for benign prostate hyperplasia at the Urology Unit of the Korle Bu Teaching Hospital in Accra. The study period was from January 2010 to September 2013 and approved by the Ethical and Protocol committee of the Korle Bu Teaching Hospital under the Medical Directorate. The diagnosis of BPH was made on the basis of the patient's clinical presentation and the finding of a prostate with benign features on digital rectal examination. Patients noted to have abnormal digital rectal examination or elevated total PSA had transrectal ultrasound guided prostate biopsy (12 cores) for histological confirmation of $\mathrm{BPH}$.

Four consultant urologists and three senior urology residents carried out the operations in this study. The total number of open prostatectomy for $\mathrm{BPH}$ that had been performed by the consultants prior to the study ranged from $80-600$ while that of the residents was $10-25$ cases.

The surgical method used was either a transvesical open prostatectomy or Millins retropubic prostatectomy as described in Campbell Urology $7^{\text {th }}$ Edition (2007) [12].

For the technique of the transvesical prostatectomy, the patient is positioned in the supine position and the suprapubic area shaved. The lower abdomen and external genital area are prepped and draped. A 22 or $24-\mathrm{Fr}$ Foley urethra catheter is inserted into the bladder and the bladder filled with $250 \mathrm{~mL}$ of saline and the catheter removed. A lower midline incision is made and deepened through the subcutaneous tissue. The linea alba is incised, and the rectus abdominis muscles separated in the midline. The transversalis fascia is incised to expose the space of Retzius. The peritoneum is swept cephalad to develop the prevesical space. A self-retaining Balfour retractor is placed in the incision to retract the rectus muscles laterally. The anterior bladder wall is identified, and two 2-0 Vicryl stitches are placed on each side of the midline below the peritoneal reflection. A vertical cystotomy is then made with an electrocautery and using a pair of Metzenbaum scissors, the cystotomy is extended cephalad and caudally to within $1 \mathrm{~cm}$ of the bladder neck. Several pairs of stay sutures are placed using 2-0 Vicryl on each side of the midline to facilitate exposure. A figure-of-eight suture using 0 Vicryl is placed and tied at the most caudal position of the cystotomy to prevent further extension of the cystotomy incision during blunt finger dissection of the adenoma. This suture is subsequently used to close the cystostomy as the first layer. After inspecting the bladder, a Millins retractor is placed in the bladder and used to further expose the trigone bringing the bladder neck and prostate into view. The ureteric orifices are identified and using electrocautery, a circular incision is made in the bladder mucosa distal to the trigone. Care is taken not to injure the ureteric orifices. With the use of a pair of Metzenbaum scissors, the plane between the prostatic adenoma and prostatic capsule is developed at the 6-o'clock position and once well-established plane is created posteriorly, the prostatic adenoma is enucleated using blunt dissection. At the apex, the prostatic urethra is transected using a pinch action of the two fingertips avoiding excessive traction so as to avoid 
avulsing the urethra and injuring the sphincteric mechanism. The prostatic adenoma is removed from the prostatic fossa. The prostatic fossa is then examined for discrete bleeding sites that are controlled with 3-0 vicryl suture ligatures. In addition, a 0 -vicryl suture is used to place two figure-of-eight sutures to advance the bladder mucosa into the prostatic fossa at the 5-o'clock and 7-o'clock positions at the prostatovesical junction to ensure control of the main arterial blood supply to the prostate. These maneuvers lead to complete hemostasis.

A 22 or 24-Fr 3-way Foley urethral catheter with a $30-\mathrm{mL}$ balloon is passed through the urethra into the bladder and the cystotomy incision closed in two layers. The first layer of closure is performed using the figureof-eight suture of 0 Vicryl that was placed and tied at the most caudal position of the cystotomy using it as a running suture. The previously placed $2-0$ Vicryl staysutures are tied over the first layer of closure to complete the two-layer closure completing a watertight bladder closure. Thirty milliliters of saline is placed in the balloon to ensure that the catheter balloon remains in the bladder and does not retract into the prostatic fossa. The urethral catheter is irrigated to confirm a watertight closure and to verify that haemorrhage is minimal. A small wound drain is placed via a separate stab incision lateral to the bladder and exits the skin. The rectus fascia is closed with vicryl 1 suture in a running fashion. The skin is closed with nylon $3-0$. The drain is then secured to the abdominal wall. Continuous bladder irrigation is initiated to prevent clot formation. The urethral catheter is removed on post operative day 7 and the patient discharged with the skin stitches removed on post operative day 10 .

For the operative technique in the retro-pubic open prostatectomy, the patient is positioned supine with the table placed in a mild Trendelenburg position without extension. The suprapubic area is shaved, prepped, and draped maintaining sterility. A 22 or 24-Fr Foley urethral catheter with a $30-\mathrm{mL}$ balloon is passed into the bladder and connected to a sterile closed drainage system, and the balloon is inflated with $30 \mathrm{~mL}$ of saline. For the patients with refractory retention of urine, the urethral catheter is maintained for the procedure. A lower midline incision from the umbilicus to the pubic symphysis is made and deepened through the subcutaneous tissue. The linea alba is incised and the rectus abdominis muscles separated in the midline. The transversalis fascia is incised sharply exposing the space of Retzius. The peritoneum is mobilized cephalad starting at the pubic symphysis. A self-retaining Balfour retractor is placed in the incision and widened and a well-padded, malleable blade is connected to the retractor and used to displace the bladder posteriorly and superiorly. The anterior surface of the bladder and prostate are exposed. The preprostatic adipose tissue is gently removed to expose the superficial branch of the dorsal vein complex and the puboprostatic ligaments with coagulation of the superficial branch of the dorsal vein. Next, we gain complete control of the dorsal vein complex as well as the lateral pedicles at the bladder neck, the main arterial blood supply to the prostate gland. This is achieved by firstly incising the endopelvic fascia laterally and partial transection of the puboprostatic ligaments. A 3-0 Monocryl suture on a 5/8-inch circle-tapered needle is passed in the avascular plane between the urethra and the dorsal vein complex at the apex of the prostate and tied. The lateral pedicles at the prostatovesical junction are ligated using figure-of-eight suture (vicryl 0) deep into the prostatovesical junction thus securing the main arterial blood supply to the prostate adenoma. With a sponge stick on the bladder neck to depress the bladder posteriorly, a No. 15 blade on a long handle is used to make a transverse capsulotomy in the prostate $2.0 \mathrm{~cm}$ distal to the bladder neck. The incision is deepened to thelevel of the adenoma and extended laterally in each direction to permit complete enucleation. A pair of Metzenbaum scissors is used to dissect the overlying prostatic capsule from the underlying prostatic adenoma. Once a well-defined plane is sufficiently developed, the index finger is inserted between the prostatic adenoma and the capsule to further develop the plane laterally and posteriorly allowing for enucleation and removal of the prostate adenoma with preservation of a strip of posterior prostatic urethra. The prostatic fossa is carefully inspected to ensure that all of the adenoma has been removed and that hemostasis is complete. A 22 or $24-\mathrm{Fr}$, three-way Foley catheter with a 30-mL balloon is inserted through the anterior urethra and prostatic fossa into the bladder and the prostatic capsule closed using viryl $2-0$ in two layers water tight with the sutures beginning laterally and meeting in the midline. Thirty milliliters of water is then placed in the balloon to ensure that the catheter balloon remains in the bladder and does not retract into the prostatic fossa. The bladder is then irrigated with saline to ensure continued hemostasis and to test the capsular closure for leakage. A suction drain is placed via a separate stab incision lateral to the prostate and bladder on one side to prevent hematoma and urinoma formation. The pelvis is irrigated with copious amounts of normal saline solution, and the rectus fascia is re-approximated with a size 1 vicryl suture. The skin is closed with interrupted nylon 3.0 sutures. The drain is secured to the abdominal wall, and traction applied to the catheter by placing gauze bandaged around the urethral catheter. Bladder irrigation is instituted until the urine become clear of blood. The urethral catheter is removed on post operative day 7 and the patient discharged with removal of the skin stitches on the $10^{\text {th }}$ post operative day.

The data collected and entered into a proforma included the pre-operative haemoglobin level $(\mathrm{Hb})$, presence of co- 
morbidities and the case type (elective or emergency). Emergency prostatectomy was performed for patients who presented with severe haematuria due to $\mathrm{BPH}$ or sepsis from indwelling/stuck catheters as part of their resuscitation. The other parameters documented included the indication for the surgery, the anaesthetic method used, the systolic pressure at start of the operation, the status of the operating surgeon (i.e. consultant or resident), the duration of surgery, the operative prostate weight and the estimated blood loss. The requirement of blood transfusion including the units of blood transfused was documented.

The decision to transfuse blood intra-operatively was based on pallor of the mucous membranes, blood pressure instability and difficulty maintaining oxygen saturation intra-operative and/or haemoglobin levels determined by using the HemoCue. For the post-operative assessment of the haemoglobin level, Standard laboratory determined haemoglobin levels using a BC-6800 hematology Analyzer by Mindray was used with haemoglobin level less than $8.0 \mathrm{~g} / \mathrm{dl}$ serving as a trigger for blood transfusion post operatively. The enucleated prostate specimens were submitted for histopathological examination.

The data was analyzed using the statistical package for the social sciences (SPSS) version 21 with the results presented as percentages and mean with standard deviation. Categorical variables were analyzed by chi-square. A significant statistical difference was accepted whenever $p<.05$. Blood transfusion and pre-operative haemoglobin, were evaluated as categorical data.

A multivariable logistic regression analysis was performed using the variables pre-operative haemoglobin level, duration of surgery, age, ASA score, systolic blood pressure, type of anaesthesia, status of the operating surgeon and operative prostate weight.

\section{Results}

\section{Patient characteristics}

Two hundred patients who had open prostatectomy for $\mathrm{BPH}$ were studied.

The majority of the patients $136(68.0 \%)$ had refractory retention of urine as the indication for surgery (Table 1).
The mean age of the patients was $69.1 \pm 9.1$ year (range $48-92$ years) with mean body weight of $70.8 \pm 12.6 \mathrm{~kg}$. The mean pre-operative haemoglobin level was $12.0 \pm 2.4 \mathrm{~g} / \mathrm{dl}$ and that of the systolic blood pressure at the start of surgery was $152.2 \pm 21.8 \mathrm{mmHg}$ (range 102-219 $\mathrm{mmHg}$ ). The mean surgery time (duration of Surgery) was $101.3 \pm$ $32.5 \mathrm{mins}$ with that of the estimated blood loss being $365.8 \pm 226.1 \mathrm{mls}$. The mean operative prostate weight was $110.5 \pm 90.5 \mathrm{~g}$ (Table 2).

Ninety (45\%) of the patients had associated comorbidities comprising hypertension 75 (37.5 \%) [Including one person with hypertension and asthma], diabetes mellitus alone $4(2.0 \%)$, hypertension with diabetes mellitus 10 (5.0 \%) and bronchial asthma 1 (0.5\%).

One hundred and sixty-seven $(83.5 \%)$ of the cases were elective cases while $33(16.5 \%)$ were emergencies.

Eighty-eight of the surgeries (44.0\%) were performed by senior residents in urology while $112(56.0 \%)$ were carried out by consultant urologists. Open transvesical prostatectomy was the operative method used in 180 $(90.0 \%)$ of the cases whilst retropubic prostatectomy was in 20 (10.0\%). Spinal, general and epidural anaesthesia were used in 164 (82.0\%), $28(14.0 \%)$ and $8(4.0 \%)$ of the operations respectively. Forty-seven (23.5\%) of the cases were transfused while 153 (76.5\%) were not (Table 3).

A total of 95 units of blood were transfused with an overall transfusion rate of $23.5 \%(47 / 200)$ (Table 4).

After histological review of the enucleated prostate specimen, two cases $(1 \%)$ had foci of adenocarcinoma but the rest were confirmed as benign prostate hyperplasia. None of the patients with foci of adenocarcinoma was transfused.

\section{Relationship between the blood transfusion rate and various patient characteristics}

Certain individual parameters had varied influence on the transfusion rate. The transfusion rate was significantly higher in patients with anaemia $(p=.000)$, emergency cases $(p=.000)$, the use of general anaesthesia $(p=.002)$, a resident as the operating surgeons $(p=.034)$, prostate weight $>100 \mathrm{~g}(p=.000)$ and duration of surgery $(p=.011)$ (Tables 5, 6 and 7).

Table 1 Indications for open prostatectomy

\begin{tabular}{lc}
\hline Indication for open prostatectomy & Number of patients (\%) \\
\hline Refractory retention of urine & $136(68.0)$ \\
Haematuria due to BPH & $45(22.5)$ \\
Lower urinary tract symptoms & $10(5.0)$ \\
BPH with associated bladder calculi & $4(2.0)$ \\
BPH with associated mild renal dysfunction & $2(1.0)$ \\
Refractory retention of urine with stuck urethral catheter & $3(1.5)$ \\
Total & $200(100)$ \\
\hline
\end{tabular}


Table 2 Patients characteristics

\begin{tabular}{lllllll}
\hline & Age (yrs) & $\begin{array}{l}\text { Pre-operative } \\
\mathrm{Hb}(\mathrm{g} / \mathrm{dl})\end{array}$ & $\begin{array}{l}\text { Systolic Blood } \\
\text { pressure }(\mathrm{mmHg})\end{array}$ & $\begin{array}{l}\text { Surgery Time } \\
\text { (duration of surgery) }[\mathrm{mins}]\end{array}$ & Estimated blood loss (ml) & $\begin{array}{l}\text { Operative } \\
\text { prostate weight (g) }\end{array}$ \\
\hline Mean & 69.0859 & 11.9943 & 152.1632 & 101.3100 & 365.7895 & 110.5094 \\
Median & 69.0000 & 12.6000 & 150.0000 & 95.0000 & 300.0000 & 80.0000 \\
Mode & 75.00 & 13.30 & $140.00(\mathrm{a})$ & 90.00 & 300.00 & 60.00 \\
Std. Deviation & 9.14562 & 2.36919 & 21.75062 & 32.49003 & 226.11000 & 90.45363 \\
Range & 44.00 & 13.30 & 117.00 & 205.00 & 900.00 & 535.00 \\
Minimum & 48.00 & 3.10 & 102.00 & 35.00 & 100.00 & 15.00 \\
Maximum & 92.00 & 16.40 & 219.00 & 240.00 & 1000.00 & 550.00 \\
\hline
\end{tabular}

Table 3 Patients characteristics (categories)

\begin{tabular}{|c|c|c|}
\hline VARIABLE & Number of patients & $\%$ \\
\hline \multicolumn{3}{|l|}{ Blood Transfusion } \\
\hline Transfused & 47 & 23.5 \\
\hline Not-transfused & 153 & 76.5 \\
\hline \multicolumn{3}{|l|}{ Age $(n=198)$} \\
\hline$\leq 70$ yrs & 109 & 55.1 \\
\hline$>70 \mathrm{yrs}$ & 89 & 44.9 \\
\hline \multicolumn{3}{|l|}{ Co-Morbidities } \\
\hline No comorbidities & 110 & 55.0 \\
\hline Presence of comorbidities & 90 & 45.0 \\
\hline \multicolumn{3}{|l|}{ Case Type } \\
\hline Elective & 167 & 83.5 \\
\hline Emergency & 33 & 16.5 \\
\hline \multicolumn{3}{|l|}{ Status of Surgeon } \\
\hline Consultant & 112 & 56.0 \\
\hline Resident & 88 & 44.0 \\
\hline \multicolumn{3}{|l|}{ Anaestheisa used } \\
\hline Spinal anesthesia & 164 & 82.0 \\
\hline General anaesthesia & 28 & 14.0 \\
\hline Epidural & 8 & 4.0 \\
\hline \multicolumn{3}{|l|}{ Operative Method used } \\
\hline Transvesical prostatectomy & 180 & 90.0 \\
\hline Millins retropubic prostatectomy & 20 & 10.0 \\
\hline \multicolumn{3}{|l|}{ Operative Prostate weight } \\
\hline Prostate weight $\leq 100 \mathrm{~g}$ & 130 & 65.0 \\
\hline Prostate weight $>100 \mathrm{~g}$ & 70 & 35.0 \\
\hline \multicolumn{3}{|l|}{ Duration of surgery } \\
\hline Surgery time $\leq 90 \mathrm{mins}$ & 95 & 47.5 \\
\hline Surgery time $>90$ mins & 105 & 52.5 \\
\hline Total & 200 & \\
\hline
\end{tabular}

For patients with severe anaemia (pre-operative blood haemoglobin level $<8.0 \mathrm{~g} / \mathrm{dl}$ ), the transfusion rate was $92.3 \%$ while the transfusion rate for those with normal pre-operative blood haemoglobin level $\geq 13.0 \mathrm{~g} / \mathrm{dl}$ was $5.5 \%$ (Table 6). The patients with $\mathrm{Hb}<8$ that were not transfused were emergency cases who underwent the procedure without blood being available in the blood bank. They however kept their haemodynamic stability after the procedure and hence no further transfusions were offered them.

\section{Multivariable logistic regression}

In a multivariable logistic regression analysis using the variables pre-operative haemoglobin level (evaluated as categorical), duration of surgery, age, ASA score, systolic blood pressure, type of anaesthesia, status of the operating surgeon and operative prostate weight, only the pre-operative haemoglobin level(as categorical data) ( $p=.000$, Odds Ratio (OR) $=0.95,95 \%$ Confidence Interval (CI) [0.035-0.257]) and duration of surgery (as a continuous data) $(p=.025$, Odds Ratio $(\mathrm{OR})=1.021,95 \%$ Confidence Interval (CI) [1.003-1.039]) could predict the likelihood of blood transfusion in open prostatectomy for BPH (Table 8).

\section{Discussion}

Peri-operative blood transfusion is common in open prostatectomy for $\mathrm{BPH}$ and that remains a significant disadvantage. The reported peri-operative blood transfusion rate has ranged widely from $3.3 \%$ to $36.8 \%$ being $3.3 \%$ in a report by Zargooshi J (Iran) [6], $24.5 \%$ by Elshai

Table 4 Number of units of blood transfused

\begin{tabular}{ll}
\hline Units of blood transfused & Number of patients (\%) \\
\hline 0 & $153(76.5)$ \\
1 & $13(6.5)$ \\
2 & $25(12.5)$ \\
3 & $5(2.5)$ \\
$\geq 4$ & $4(2.0)$ \\
Total & $200(100)$ \\
\hline
\end{tabular}


Table 5 Blood transfusion against age, systolic blood pressure and enucleated prostate weight

\begin{tabular}{|c|c|c|c|c|c|c|}
\hline & & & \multicolumn{2}{|c|}{ Blood Transfusion } & \multirow[t]{2}{*}{ Total } & \multirow[t]{2}{*}{$p$-value } \\
\hline & & & Not-transfused & Transfused & & \\
\hline \multirow[t]{4}{*}{ Patient age } & Age $\leq 70$ yrs & Count & 83 & 26 & 109 & \\
\hline & & $\%$ within transfusion & $55.0 \%$ & $55.3 \%$ & $55.1 \%$ & \\
\hline & Age $>70$ yrs & Count & 68 & 21 & 89 & \\
\hline & & $\%$ within transfusion & $45.0 \%$ & $44.7 \%$ & $44.9 \%$ & \\
\hline Total & & Count & 151 & 47 & 198 & 0.551 \\
\hline \multirow[t]{4}{*}{ Systolic blood pressure } & Systolic blood pressure $\leq 140 \mathrm{mmHg}$ & Count & 56 & 17 & 73 & \\
\hline & & $\%$ within transfusion & $36.6 \%$ & $36.2 \%$ & $36.5 \%$ & \\
\hline & Systolic blood pressure $>140 \mathrm{mmHg}$ & Count & 97 & 30 & 127 & \\
\hline & & $\%$ within transfusion & $63.4 \%$ & $63.8 \%$ & $63.5 \%$ & \\
\hline Total & & Count & 153 & 47 & 200 & 0.551 \\
\hline \multirow[t]{4}{*}{ Enucleated Prostate weight } & Prostate weight $\leq 100 \mathrm{~g}$ & Count & 111 & 19 & 130 & \\
\hline & & $\%$ within transfusion & $72.5 \%$ & $40.4 \%$ & $65.0 \%$ & \\
\hline & Prostate weight $>100 \mathrm{~g}$ & Count & 42 & 28 & 70 & \\
\hline & & $\%$ within transfusion & $27.5 \%$ & $59.6 \%$ & $35.0 \%$ & \\
\hline \multirow[t]{2}{*}{ Total } & & Count & 153 & 47 & 200 & \\
\hline & & $\%$ within transfusion & $100.0 \%$ & $100.0 \%$ & $100.0 \%$ & 0.000 \\
\hline
\end{tabular}

et al (Egypt) [7] and $36.8 \%$ by Ngugi et al (Kenya) [8]. The blood transfusion rate of $23.5 \%$ in the present study compares with some of these reports.

Different factors have been reported to play a role in determining the need for blood transfusion in open prostatectomy for BPH. Previous reports have indicated that patient factors such as age above 70 years, increasing ASA scores and a systolic blood pressure above $140 \mathrm{mmHg}$ might contribute to the need for blood transfusion in open prostatectomy [8]. These factors were not observed to be significant in this study. Of interest though is the finding of an increased transfusion rate in ASA3 by TorresClaramunt $\mathrm{R}$ et al in a study on the predictors of blood transfusion in patients undergoing elective surgery for degenerative diseases of the spine [13].

This study found the presence of anaemia to be associated with a significantly higher blood transfusion rate. Using the WHO definition for anaemia, (http:// www.who.int/vmnis/indicators/haemoglobin.pdf) patients who had severe anaemia pre-operatively were more likely to be transfused compared with those with normal blood haemoglobin levels. $(p=.000)$. Hence the pre-operative blood haemoglobin level should serve as a guide to possible need for blood transfusion in open prostatectomy for BPH. Improving the blood haemoglobin level to normal levels before surgery could probably reduce the blood transfusion rate for this operation. The significantly higher blood transfusion rate in emergency cases may be partly due to inadequate pre-operative preparation before the procedure is undertaken in these rather ill patients.
Transfusion rate of $14.4 \%$ in the elective cases is comparable to that of $8.2 \%$ reported by Serrata et al. [14].

There was an observed lower blood transfusion rate in patients with co-morbidities as compared to patients without any co-morbidities $(p=.051)$. The reason for this was not obvious. A possible explanation could be that those with co-morbidities had a more rigorous preoperative preparation before surgery.

A significantly higher blood transfusion rate was observed in the operations performed under general anaesthesia. $(p=.002)$ It is noteworthy that an increased use of blood transfusion associated with general anaesthesia has been observed in relation to total hip arthroplasty by Maurer et al. [15].

Although no significant difference was found between the two standard operative techniques for open prostatectomy in this study $(p=.345)$, Dall'Oglio et al reported a reduced transfusion rate in an improved technique of Millin's retropubic prostatectomy compared to a classical transvesical prostatectomy [16].

The availability of surgeons specially trained in the procedure of open prostatectomy for $\mathrm{BPH}$ is not uniform across countries and even within a particular country. In some developing countries open prostatectomy is carried out by general surgeons [5] and in others, a significant proportion of the procedures are done by residents in training [7]. The attendant differences in experience and expertise of these categories of surgeons in performing open prostatectomy may partly be responsible for the wide variation in the reported transfusion rates for the procedure from 
Table 6 Blood transfusion against Hb, case type and co-morbidities

\begin{tabular}{|c|c|c|c|c|c|c|}
\hline & & & \multicolumn{2}{|c|}{ Blood Transfusion } & \multirow[t]{2}{*}{ Total } & \multirow[t]{2}{*}{$p$-value } \\
\hline & & & Not-transfused & Transfused & & \\
\hline \multirow[t]{8}{*}{ Hb Level } & Severe Anaemia $(\mathrm{Hb}<8.0 \mathrm{~g} / \mathrm{dl})$ & Count & 1 & 12 & 13 & \\
\hline & & $\%$ within transfusion & $.7 \%$ & $25.5 \%$ & $6.5 \%$ & \\
\hline & Moderate Anaemia (Hb 8.0-10.9 g/dl) & Count & 23 & 21 & 44 & \\
\hline & & $\%$ within transfusion & $15.0 \%$ & $44.7 \%$ & $22.0 \%$ & \\
\hline & Mild Anaemia (11.0-12.9 g/dl) & Count & 43 & 9 & 52 & \\
\hline & & $\%$ within transfusion & $28.1 \%$ & $19.1 \%$ & $26.0 \%$ & \\
\hline & Normal $(\geq 13.0 \mathrm{~g} / \mathrm{dl})$ & Count & 86 & 5 & 91 & \\
\hline & & $\%$ within transfusion & $56.2 \%$ & $10.6 \%$ & $45.5 \%$ & \\
\hline Total & & Count & 153 & 47 & 200 & 0.000 \\
\hline \multirow[t]{4}{*}{ Case type } & Elective & Count & 143 & 24 & 167 & \\
\hline & & $\%$ within transfusion & $93.5 \%$ & $51.1 \%$ & $83.5 \%$ & \\
\hline & Emergency & Count & 10 & 23 & 33 & \\
\hline & & $\%$ within transfusion & $6.5 \%$ & $48.9 \%$ & $16.5 \%$ & \\
\hline Total & & Count & 153 & 47 & 200 & 0.000 \\
\hline \multirow[t]{10}{*}{ Co-morbidities } & No co-morbidity & Count & 76 & 34 & 110 & \\
\hline & & $\%$ within transfusion & $49.7 \%$ & $72.3 \%$ & $55.0 \%$ & \\
\hline & Hypertension & Count & 66 & 9 & 75 & \\
\hline & & $\%$ within transfusion & $43.1 \%$ & $19.1 \%$ & $37.5 \%$ & \\
\hline & Diabetes Mellitus & Count & 3 & 1 & 4 & \\
\hline & & $\%$ within transfusion & $2.0 \%$ & $2.1 \%$ & $2.0 \%$ & \\
\hline & Hypertension with diabetes Mellitus & Count & 7 & 3 & 10 & \\
\hline & & $\%$ within transfusion & $4.6 \%$ & $6.4 \%$ & $5.0 \%$ & \\
\hline & Asthma & Count & 1 & 0 & 1 & \\
\hline & & $\%$ within transfusion & $.7 \%$ & $0.0 \%$ & $.5 \%$ & \\
\hline \multirow[t]{2}{*}{ Total } & & Count & 153 & 47 & 200 & \\
\hline & & $\%$ within transfusion & $100.0 \%$ & $100.0 \%$ & $100.0 \%$ & 0.051 \\
\hline
\end{tabular}

different parts of the world. The present study showed that in our centre, the blood transfusion rate was significantly higher in the residents with less experience compared to that of the consultants with more experience in performing this surgery ( $30.7 \%$ vrs $17.9 \%$ [ $p=.034]$.

The finding of a significant association between the blood transfusion rate and the duration of surgery is indicative of an increased likelihood of transfusion with a longer duration of surgery. Comparing the blood transfusion rate and the mean prostate weight in various series showed no pattern of an increased blood transfusion with increasing mean prostate weights. Blood transfusion rates of $12.7 \%, 6.8 \%, 36.8 \%$ and $8.2 \%$ have been reported in procedures with mean prostate weights of $88.7 \mathrm{~g}, 104.5 \mathrm{~g}, 66.9 \mathrm{~g}$ and $75 \mathrm{~g}$ respectively [1, 4, 8, 14]. In this study a blood transfusion rate of $23.5 \%$ was observed corresponding to a mean prostate weight of $110.5 \mathrm{~g}$. Suer et al reported an increased blood transfusion rate of $19.2 \%$ for prostates greater than $100 \mathrm{~g}$ compared to those with prostate weight less than $100 \mathrm{~g}$ (9.4 \%) [4]. Elshai et al upon stratification found no increase in blood transfusion rates between prostate weights greater than or less than $120 \mathrm{~g}$ [7]. This study confirmed the findings of Suer et al as the blood transfusion rate was significantly higher in prostates $>100 \mathrm{~g}(40.0 \%)$ compared with prostate weights $\leq 100.0 \mathrm{~g}(14.6 \%)[p=.000]$. Even though there are currently methods for surgical resection of large prostates such as HoLEP, ThuLRP and PVP which have been found safe and effective and probable requiring less blood transfusion, [3] open prostatectomy is still used for large prostates in low resource countries like Ghana due to unavailability of these other treatment modalities.

Of the various factors which were found to be associated significantly with increased blood transfusion rate, only the pre-operative blood haemoglobin level (as categorical data) $(p=.000$, OR 0.95, $95 \%$ CI [0.035-0.257]) and the duration of surgery (as continuous data) $(p=.025$, OR 1.02 , $95 \% \mathrm{CI}[1.003-1.039])$ could predict the likelihood of 
Table 7 Blood transfusion against type of anaesthesia, status of surgeon, operative method and duration of surgery

\begin{tabular}{|c|c|c|c|c|c|c|}
\hline & & & Blood Transfusic & & Total & $p$-value \\
\hline & & & Not-transfused & Transfused & & \\
\hline Anesthesia & Spinal & Count & 132 & 32 & 164 & \\
\hline & & $\%$ within transfusion & $86.3 \%$ & $68.1 \%$ & $82.0 \%$ & \\
\hline & Ga & Count & 14 & 14 & 28 & \\
\hline & & $\%$ within transfusion & $9.2 \%$ & $29.8 \%$ & $14.0 \%$ & \\
\hline & Epidural & Count & 7 & 1 & 8 & \\
\hline & & $\%$ within transfusion & $4.6 \%$ & $2.1 \%$ & $4.0 \%$ & \\
\hline Total & & Count & 153 & 47 & 200 & 0.002 \\
\hline Status of operating surgeon & Consultant & Count & 92 & 20 & 112 & \\
\hline & & $\%$ within transfusion & $60.1 \%$ & $42.6 \%$ & $56.0 \%$ & \\
\hline & Resident & Count & 61 & 27 & 88 & \\
\hline & & $\%$ within transfusion & $39.9 \%$ & $57.4 \%$ & $44.0 \%$ & \\
\hline Total & & Count & 153 & 47 & 200 & 0.034 \\
\hline Operative method & Transvesical & Count & 136 & 44 & 180 & \\
\hline & & $\%$ within transfusion & $88.9 \%$ & $93.6 \%$ & $90.0 \%$ & \\
\hline & Retropubic & Count & 17 & 3 & 20 & \\
\hline & & $\%$ within transfusion & $11.1 \%$ & $6.4 \%$ & $10.0 \%$ & \\
\hline Total & & Count & 153 & 47 & 200 & \\
\hline & & $\%$ within transfusion & $100.0 \%$ & $100.0 \%$ & $100.0 \%$ & 0.345 \\
\hline Duration of Surgery & Surgery time $\leq 90 \mathrm{mins}$ & Count & 80 & 15 & 95 & \\
\hline & & $\%$ within transfusion & $52.3 \%$ & $31.9 \%$ & $47.5 \%$ & \\
\hline & Surgery time $>90$ mins & Count & 73 & 32 & 105 & \\
\hline & & $\%$ within transfusion & $47.7 \%$ & $68.1 \%$ & $52.5 \%$ & \\
\hline Total & & Count & 153 & 47 & 200 & \\
\hline & & $\%$ within transfusion & $100.0 \%$ & $100.0 \%$ & $100.0 \%$ & 0.011 \\
\hline
\end{tabular}

Table 8 Multivariable logistic regression analysis

\begin{tabular}{|c|c|c|c|c|c|c|c|c|}
\hline \multicolumn{9}{|l|}{ Variables in the Equation } \\
\hline \multirow[t]{2}{*}{ Predictor Variables } & \multirow[t]{2}{*}{ B } & \multirow[t]{2}{*}{ S.E. } & \multirow[t]{2}{*}{ Wald (chi-square) } & \multirow[t]{2}{*}{$d f$} & \multirow[t]{2}{*}{$p$-value } & \multirow[t]{2}{*}{ odd ratio } & \multicolumn{2}{|c|}{$95 \%$ C.I.for odd ratio } \\
\hline & & & & & & & Lower & Upper \\
\hline Pre-operative Hb (Anaemia) & -2.352 & .507 & 21.517 & 1 & .000 & .095 & .035 & .257 \\
\hline Surgery time (Duration of surgery) & .020 & .009 & 5.021 & 1 & .025 & 1.021 & 1.003 & 1.039 \\
\hline Age category & -.212 & .616 & .119 & 1 & .730 & .809 & .242 & 2.705 \\
\hline ASA score & -.369 & .475 & .605 & 1 & .437 & .691 & .273 & 1.753 \\
\hline Systolic blood pressure & -.120 & .334 & .128 & 1 & .720 & .887 & .461 & 1.708 \\
\hline Anesthesia & .585 & .648 & .814 & 1 & .367 & 1.794 & .504 & 6.390 \\
\hline Status of operating surgeon & 1.039 & .618 & 2.828 & 1 & .093 & 2.827 & .842 & 9.489 \\
\hline Operative prostate weight & .003 & .004 & .524 & 1 & .469 & 1.003 & .996 & 1.010 \\
\hline Constant & 1.651 & 2.384 & .479 & 1 & .489 & 5.211 & & \\
\hline
\end{tabular}

Therefore, the multivariable logistic regression is given by

$\log ($ transfused $)=1.651-2.352 \times 1+0.020 \times 2-0.212 \times 3-0.369 X 4-0.120 \times 5+0.585 \times 6+1.039 \times 7+0.003 \times 8$

Variable(s) entered on step 1: hb (anaemia), surgery time, age category, ASA score, systolic, anaesthesia, status of surgeon, operative prostate weight 
blood transfusion in open prostatectomy for $\mathrm{BPH}$ following a multivariable logistic regression analysis.

\section{Conclusions}

Various factors were found to be associated significantly with increased blood transfusion rate in open prostatectomy for $\mathrm{BPH}$. These included the presence of anaemia, emergency cases, use of general anaesthesia, prostate weight $>100 \mathrm{~g}$, duration of surgery and a resident as the operating surgeon. However, only the pre-operative blood haemoglobin level and the duration of surgery could predict the likelihood of blood transfusion in open prostatectomy for $\mathrm{BPH}$.

For patients with normal blood haemoglobin level $(\mathrm{Hb} \geq 13.0 \mathrm{~g} / \mathrm{dl})$, a 'group and save' policy should be the preferred blood ordering procedure if undergoing an elective open prostatectomy for $\mathrm{BPH}$, which preferably should be performed under spinal anaesthesia.

\section{Competing interests}

There are no financial or non- financial competing interests to declare.

\section{Authors' contributions}

MYK- was involved in conception and design of the study, contributed surgical expertise, involved in data collection and drafting of the final manuscript. GOK- was involved in conception and design of the study, contributed surgical expertise and offered a critical review of the manuscript for intellectual content. JEM- was involved in conception and design of the study, offered surgical expertise and also data collection. SGA- contributed surgical expertise and offered a critical review of the manuscript for intellectual content. KA- offered surgical expertise and data collection. BT- offered surgical expertise and data collection. EDY: Offered a critical review of the manuscript for intellectual content. All the authors have read and approved the final version of the manuscript.

\section{Acknowledgements}

We want to acknowledge Mr Yao Ahonon of the Public Health Department of the Korle Bu Teaching Hospital for his assistance with the statistical analysis. No external funding was obtained for this work.

Received: 3 July 2014 Accepted: 17 March 2016

Published online: 28 March 2016

\section{References}

1. Varkarakis I, Kyriakakis Z, Delis A, Protogerou V, Deliveliotis C. Long-term results of open transvesical prostatectomy from a contemporary series of patients. Urol. 2004;64:306-10.

2. Oelke M, Bachmann A, Descazeaud A, Emberton M, Gravas S, Michel MC, N'Dow J, Nordling J, de la Rossette JJ: EAU Guidelines on the treatment and follow-up of Non-neurogenic Male Lower Urinary Tract Symptoms including Benign Prostatic Obstruction. Eur Urol. 2013;64:118-140 [http://dx.doi.org/10. 1016/j.eururo.2013.03.004].

3. Kuntz RM, Lehrich K, Ahyai SA. Holmium laser enucleation of the prostate versus open prostatectomy for prostates greater than $100 \mathrm{~g}$ : 5- year follow up results of a randomized clinical trial. Eur Urol. 2008:53:160-6.

4. Suer E, Gokce I, Yaman O, Anafarta K, Gogus O. Open prostatectomy is still a valid option for large prostates: a high-volume, single-center experience. Urol. 2008;72:90-4.

5. Tubaro A, de Nunzio C. The current role of open surgery in BPH. EAU-EBU Update series. 2006;14:191-201.

6. Zargooshi J. Open prostatectomy for benign prostate hyperplasia: short-term outcome in 3000 consecutive patients. Prostate Cancer Prostatic Dis. 2007;10: 374-7.

7. Elshai AM, El-Nahas AR, Barakat TS, Elsaadany MM, El-Hefnawy AS. Transvesica open prostatectomy for benign prostate hyperplasia in the era of minimally invasive surgery: peri-operative outcomes of a contemporary series. Arab J Urol. 2013;11:362-8.

8. Ngugi PM, Saula PW. Open simple prostatectomy and blood transfusion in Nairobi. East African Med J. 2007:84 suppl 9:12-23.

9. Hendrickson JE, Hillyer CD. Noninfectious serious hazards of transfusion. Anaesth Analg. 2009;108:759-69.

10. Perkins HA, Busch MP. Transfusion-associated infections: 50 years of relentless challenges and remarkable progress. Transfusion. 2010;50:2080-99.

11. Whitaker Bl, Green J, King MR, Leibeg LL, Mathew SM, Schlumpf KS, Schrieber GB: The 2007 national blood collection and utilization survey report. Washington: Department of Health and Human services; 2007. www.hhs.gov/ash/bloodsafety/ 2007nbcus \survey.pdf.

12. Han M, Partin AW. Retropubic and Suprapubic Open Prostatectomy. In: Kavoussi LR, Novick AC, Partin AW, editors. Campbell-Walsh Urology $9^{\text {th }}$ Edition. Philadelphia: Saunders Elsevier; 2007. p. 2845-53.

13. Torres-Claramunt R, Ramírez M, López-Soques M, Saló G, Molina-Ros A, Lladó A, Cáceres E: Predictors of blood transfusion in patients undergoing elective surgery for degenerative conditions of the spine. Arch Orthop Trauma Surg. 2012;132:1393-8.

14. Serretta V, Morgia G, Fondacaro L, Curto G, Lo bianco A, Pirritano D, Melloni D, Orestano F, Motta M, Pavone-Macaluso M: Open prostatectomy for benign prostatic enlargement in southern Europe in the late 1990s: a contemporary series of 1800 interventions. Urol. 2002;60:623-7.

15. Maurer SG, Chen AL, Hiebert R, Pereira GC, Di Cesare PE. Comparison of outcomes of using spinal versus general anesthesia in total hip arthroplasty. Am J Orthop. 2007:36:E101-6.

16. Dall'Oglio MF, Srougi M, Antunes AA, Crippa A, Cury J. An improved technique for controlling bleeding during simple retropubic prostatectomy: a randomized controlled study. BJU Int. 2006;98:384-7.
Submit your next manuscript to BioMed Central and we will help you at every step:

- We accept pre-submission inquiries

- Our selector tool helps you to find the most relevant journal

- We provide round the clock customer support

- Convenient online submission

- Thorough peer review

- Inclusion in PubMed and all major indexing services

- Maximum visibility for your research

Submit your manuscript at www.biomedcentral.com/submit
) Biomed Central 